Volume 9, No.5, September - October 2020

International Journal of Advanced Trends in Computer Science and Engineering

Available Online at http://www.warse.org/IJATCSE/static/pdf/file/ijatcse220952020.pdf

https://doi.org/10.30534/ijatcse/2020/220952020

\title{
Solving Multi-Objective Transportation Problem Using Opportunity Cost Method
}

\author{
EmanOun $^{1}$, HegazyZaher ${ }^{2}$, Samia Mohammed ${ }^{3}$ \\ ${ }^{1}$ Doctor in Operations Research, Faculty of Graduate Studies for Statistical Research, Cairo University, Egypt, \\ a.eyman@yahoo.com \\ ${ }^{2}$ Prof. in Statistics,Faculty of Graduate Studies for Statistical Research, Cairo University, Egypt, \\ hgsabry@yahoo.com \\ ${ }^{3} \mathrm{Ph}$. D Student in Operations Research, Faculty of Graduate Studies for Statistical Research, Cairo University,
} Egypt

\section{ABSTRACT}

In this paper, a simple method is proposed to get the best compromise solution of linear multi-objective transportation problem (MOTP). After getting the greater cost matrix, it is used the idea of opportunity cost method to get the solution. Using this method, we get an efficient solution, which is liked by decision maker. Also this method is simple and has less time. For the application of proposed method, numerical example is tested from the literature and is solved with proposed method which proved its efficiency.

Key words: Multi-objective decision making problem, Multiobjective transportation problem, Opportunity cost method.

\section{INTRODUCTION}

Transportation problem (TP) is a special class of linear programming problem which deals with the distribution of the commodity from sources to destinations. To obtain the initial basic feasible solution, there are several methods as north-west corner method (NWC), least-cost method, and the Vogel's approximation method. The best method of them is the Vogel's approximation method (VAM), which yields the best initial basic feasible solution. Also there are several methods developed to solve the TP. A lot of factors affect deciding the objective functions like traffic quality which should be optimized like described in [1].The collected data about the problem is very important which help to get the real optimal solution of the problem like mentioned in [2].Recently TP could contain more than one objective function like transportation cost, delivery time ... etc. which is called multi objective transportation problem (MOTP). The aim of solving MOTP is getting an efficient set of compromise solution for the problem.

To solve MOTP there are several methods was proposed.

Ebrahim A. (1995) proposed a new approach to find all efficient solutions for the vector optimization problem without using any parameters [3].

Abd El-Wahed W. (2001) presented a fuzzy programming approach to determine the optimal compromise solution to multi-objective transportation problem [4].

Waiel F. et al (2006) proposed the interactive fuzzy goal approach, which combination the goal programming, fuzzy programming, and interactive programming in one methodology to solve the problem [5].

Pandian P. et al. (2011) proposed a new method named dripping method to solve Bi-objective transportation problem [6]. Pandian P. (2012) proposeda new approach, namely sum of objectives method to find a fair solution to multi-objective programming problems. His idea depends on converting the multi objective problem into single objective problem. The cost in the single objective problem in every cell is a summation of the costs in the same cell in all objectives matrixes in the multi objective problem [7].

Abdul Quddoos S. et al. (2013) proposed a new method, namely the MMK-method for finding non-degenerate compromise optimal solution for Bi-objective transportation problem [8].

Asim M. et al (2017) proposed a weighted approach based on goalprogramming to obtain the compromise solutions to the multiobjective transportation problem [9].

Murshid K. et al (2018) proposed a new model for theweighted method of goal programming based on minimizing the distances between ideal objectives to feasible objective space [10].

Rizk M, et al (2018) developed a new compromise algorithm for multi-objective transportation problem, which is inspired by Zimmermann's fuzzy programming [11].

This paper presents a new method to solve MOTP and it is organized as follows in section 2 the problem definition and the mathematical model will be presented, the third section presents the new proposed method. The discussion will be presented in section 4 and finally conclusion will be presented in the fifth section.

\section{Multi ObJective Transportation Problem}

MOTP has more than one objective, as minimizing the time and the cost or other objectives. The mathematical model of multiobjective transportation problem is as follows [8]:

$\operatorname{minz}=\sum_{i=1}^{m} \sum_{j=1}^{n} c_{i j}^{r} x_{i j}$

Subject to.

$\sum_{j=1}^{n} x_{i j}=a_{i}, \quad i=1,2, \ldots \ldots . m$. 
EmanOun et al., International Journal of Advanced Trends in Computer Science and Engineering, 9(5), September - October 2020,8438 - 8442

$$
\begin{aligned}
& \sum_{i=1}^{m} x_{i j}=b_{j}, \quad j=1,2, \ldots \ldots . . n . \\
& \sum_{i=1}^{m} a_{i}=\sum_{j=1}^{n} b_{j}, \text { and } x_{i j} \geq 0, \forall i, j
\end{aligned}
$$

Where: $a_{i}$ represent the units available at source $(i), b_{i}$ represent the units demanded at destination $(j), x_{i j}$ representthe unknown quantity shipped from source $(i)$ to destination $(j), c_{i j}$ represent the cost of shipping units from source $(i)$ to destination $(j)$.

\section{THE PROPOSED METHODS TO SOLVE MULTI OBJECTIVE TRANSPORTATION PROBLEM}

This section presents two methods the Opportunity Cost Method (OCM) to generate a set of compromise solutions to solve (MOTP).

\subsection{The OPPoRtunity Cost Method (OCM)}

The OC method is depending on three phases:

1- Converting MOTP into a single objective transportation problem (SOTP) by getting the Greater Cost matrix (GCM) which will be explained later, then solving the problem using any method, or solve any of the objectives by any method.

2- Apply the solution in the primal objectives matrixes.

3- Apply the new proposed method OCM to calculate the set of compromise solution.

\subsection{GCM to ObTaIn InITIAL SOLUTION}

The idea behind the proposed method is to identify the feasible solution that minimize all the objectives as possible, the steps of this method is as follows:

1- Converting the multi objective transportation problem into a single objective transportation problem where every cell in the new table includes the greatest cost in the same location in all objectives.

2- Solve the problem using any method.

3- Improve the solution by the proposed method OCM.

\subsection{OCM Steps to Solve Multi Objective Transportation Problem.}

The new proposed method for solving multi objective problem depends on calculating the opportunity cost as in the following steps.

\section{ThE OPPORTUNITY COST STEPS:}

1. Solve the multi-objective transportation problem dependent on (GC) matrix, or solve any of the objectives by any method.

2. Apply the solution in all objectives in the multi objective transportation problem, and record the objective value to every objective and summation of all objectives in a set of compromise solutions.

3. Calculate the opportunity cost to every objective then put the summation of opportunity costs to the cells in the same location as a penalty to this cell.

4. To update the compromise solutions set select the cell which has most negative penalty to be included in the next solution and create a loop as in stepping stone method to assign to this cell.

5. Record the objective value to every objective and summation of all objectives in a set of compromise solutions.

6. Repeat the steps from 3 to 5 until all penalties are positive.

7. Stop and present the set of compromise solutions to the decision-maker.

\section{NUMERICAL EXAMPLE:}

The following MOTP will be solved by the proposed method OCM. Suppose the three objectives of a MOTP are as follows:

$F 1=\left[\begin{array}{ccccc}9 & 12 & 9 & 6 & 9 \\ 7 & 3 & 7 & 7 & 5 \\ 6 & 5 & 9 & 11 & 3 \\ 6 & 8 & 11 & 2 & 2\end{array}\right] F^{\prime \prime}=\left[\begin{array}{lllll}2 & 9 & 8 & 1 & 4 \\ 1 & 9 & 9 & 5 & 2 \\ 8 & 1 & 8 & 4 & 5 \\ 2 & 8 & 6 & 9 & 8\end{array}\right] F 3=\left[\begin{array}{lllll}2 & 4 & 6 & 3 & 6 \\ 4 & 8 & 4 & 9 & 2 \\ 5 & 3 & 5 & 3 & 6 \\ 6 & 9 & 6 & 3 & 1\end{array}\right]$

With supplies $a_{1}=5, a_{2}=4, a_{3}=2, a_{4}=9$, and demands $b_{1}=4, b_{2}=4, b_{3}=6, b_{4}=2, b_{5}=4$.

The GCM is obtained according to previous steps as follows

$$
G C M=\left[\begin{array}{ccccc}
9 & 12 & 9 & 6 & 9 \\
7 & 9 & 9 & 9 & 5 \\
8 & 5 & 9 & 11 & 6 \\
6 & 9 & 11 & 9 & 8
\end{array}\right]
$$

, and the optimal solution of this GCM will be $[0,0,3,2,0,0,0,0,0,4,0,2,0,0,0,4,2,3,0,0]$.

- The following tables illustrates the solution improvements until getting the best solution according to the OCM such that

- Table 1 gives the values of objectives depending on the solution after applying GCM.

- Table 2 explains the first improvement of the solution.

- Table 3 explains the second improvement of the solution.

- Table 4 explains the third and last solution improvement. - The results are compared with different techniques illustrated in [5] and proved its efficiency such that the results shown in table 5 explains the results are similar to two of the compared techniques and superior on one of them. 
EmanOun et al., International Journal of Advanced Trends in Computer Science and Engineering, 9(5), September - October 2020,8438 - 8442

Table1. The Values of Objectives Depending on the Solution after Applying GCM

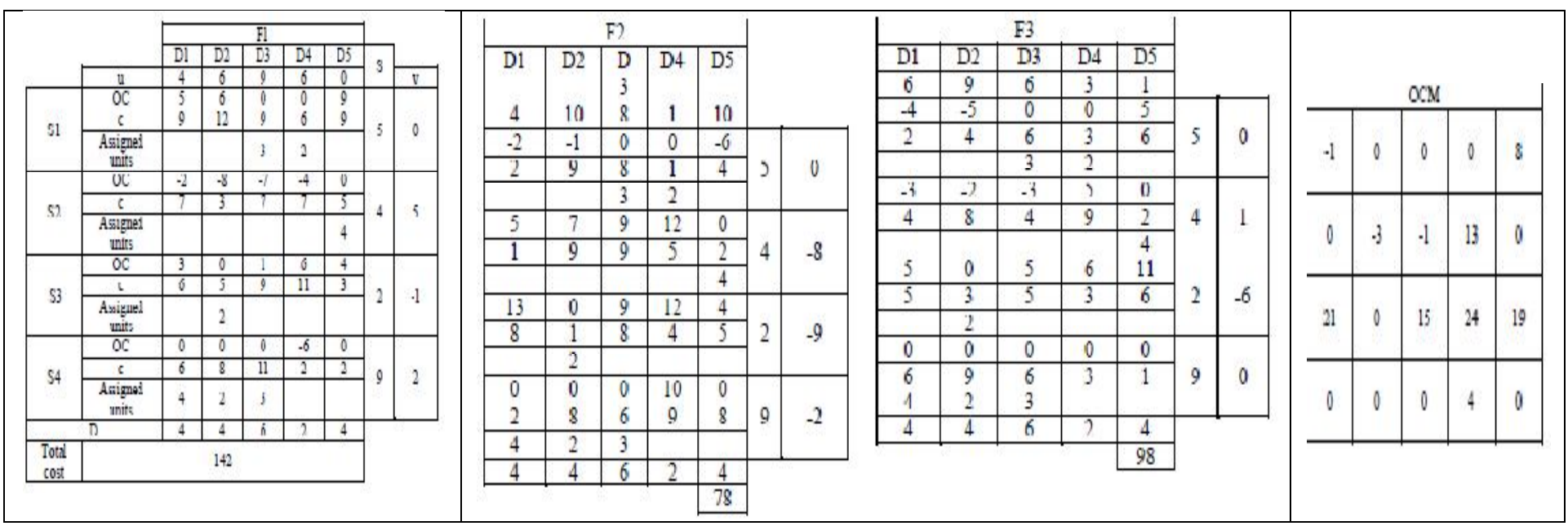

Table2. the First Impovement

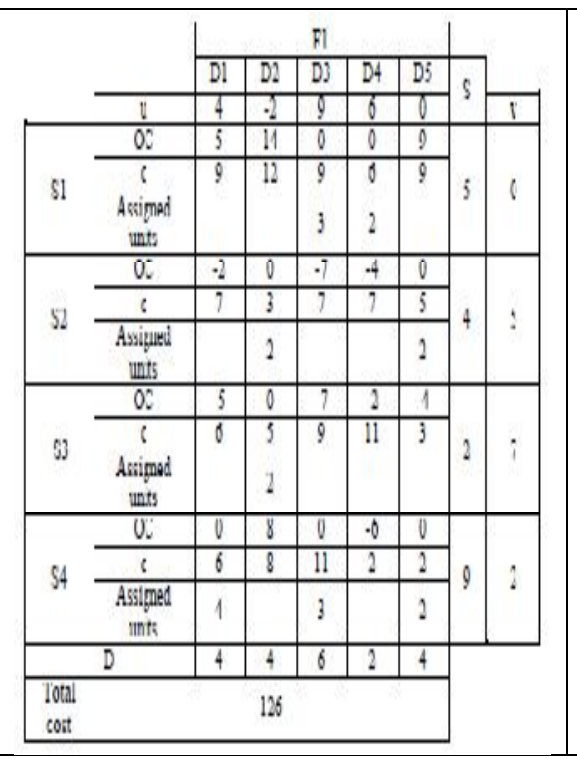

\begin{tabular}{|c|c|c|c|c|c|c|}
\hline \multicolumn{5}{|c|}{ F2 } & \\
\hline DI & D? & $\begin{array}{l}D \\
3\end{array}$ & D4 & D. & & \\
\hline 4 & 17 & 8 & 1 & 10 & & \\
\hline-2 & -8 & 0 & 0 & -6 & \multirow{3}{*}{5} & \\
\hline 2 & 9 & 8 & 1 & 4 & & 0 \\
\hline & & 3 & 2 & & & \\
\hline 5 & 0 & 9 & 12 & 0 & \multirow{3}{*}{4} & \multirow{3}{*}{-8} \\
\hline 1 & 9 & 9 & 5 & 2 & & \\
\hline & 2 & . & & 2 & & \\
\hline 20 & 0 & 16 & 19 & 1 & \multirow{3}{*}{2} & \multirow{3}{*}{-16} \\
\hline 8 & 1 & 8 & 4 & 5 & & \\
\hline & 2 & & & & & \\
\hline 0 & .7 & 0 & 10 & 0 & \multirow{3}{*}{9} & \multirow{3}{*}{-2} \\
\hline 2 & 4 & 6 & 9 & 8 & & \\
\hline 1 & & 6 & & 2 & & \\
\hline 4 & 4 & 6 & 2 & 4 & & \\
\hline
\end{tabular}

\begin{tabular}{|c|c|c|c|c|c|c|c|c|c|c|c|}
\hline \multicolumn{5}{|c|}{ F3 } & & & & & & & \\
\hline D! & D2 & D3 & D4 & DS & & & & & & & \\
\hline 6 & 7 & 6 & 3 & 1 & & & \multirow{2}{*}{\multicolumn{5}{|c|}{ OWM }} \\
\hline 4 & .3 & 0 & 0 & 5 & \multirow{3}{*}{\multicolumn{2}{|c|}{0}} & & & & & \\
\hline 2 & 4 & 6 & 3 & 6 & & & \multirow{2}{*}{\multicolumn{2}{|c|}{$\downarrow$}} & \multirow{2}{*}{0} & \multirow{2}{*}{0} & \multirow{2}{*}{8} \\
\hline & & 3 & 2 & & & & & & & & \\
\hline .3 & 0 & .3 & 5 & 0 & \multirow{3}{*}{\multicolumn{2}{|c|}{4}} & \multirow{3}{*}{0} & \multirow{3}{*}{0} & \multirow{3}{*}{-1} & \multirow{3}{*}{13} & \multirow{3}{*}{ c } \\
\hline 4 & 8 & 4 & 9 & 2 & & & & & & & \\
\hline & 2 & & & 2 & & & & & & & \\
\hline 3 & 0 & 3 & 4 & 9 & \multirow{3}{*}{2} & & \multirow{2}{*}{18} & \multirow{2}{*}{0} & \multirow{2}{*}{.2} & \multirow{2}{*}{$2 !$} & \multirow{2}{*}{16} \\
\hline 5 & 3 & 5 & 3 & 6 & & 4 & & & & & \\
\hline & 2 & & & & & & \multirow{3}{*}{0} & \multirow{3}{*}{3} & \multirow{3}{*}{0} & \multirow{3}{*}{4} & \multirow{3}{*}{ l } \\
\hline 0 & 2 & l & 0 & 0 & \multirow{3}{*}{9} & \multirow{3}{*}{0} & & & & & \\
\hline 6 & 9 & 6 & 3 & 1 & & & & & & & \\
\hline 4 & & 3 & & 2 & & & & & & & \\
\hline 4 & 4 & 6 & 2 & 4 & & & & & & & \\
\hline & & & & 94 & & & & & & & \\
\hline
\end{tabular}

Table3. The Second Improvement
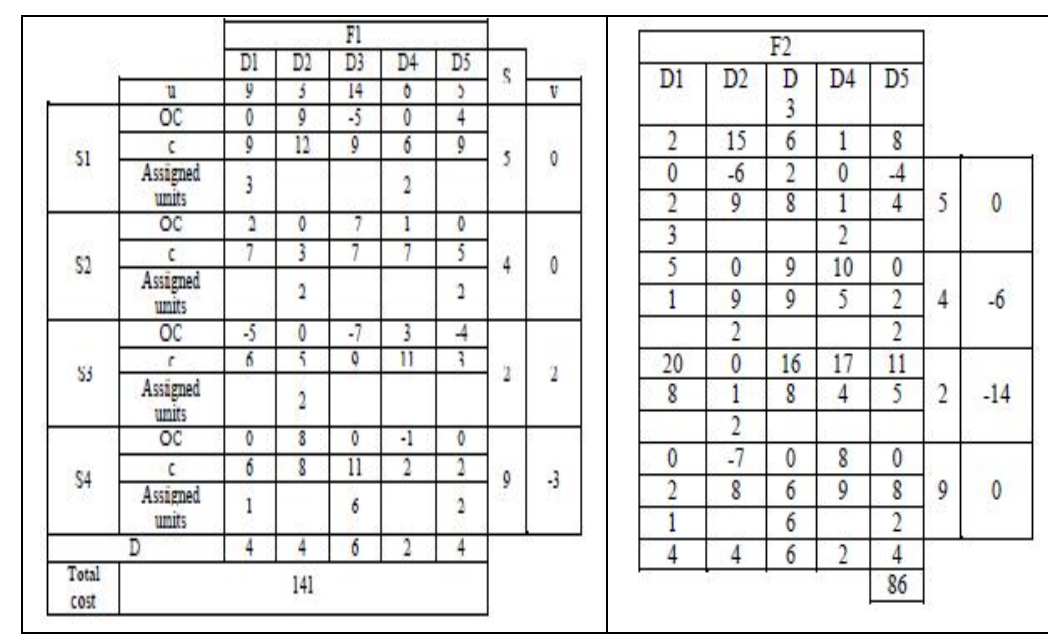

\begin{tabular}{|c|c|c|c|c|c|c|}
\hline \multicolumn{5}{|c|}{ F3 } & & \\
\hline D1 & $\mathrm{D} 2$ & D3 & D4 & $\mathrm{DS}$ & & \\
\hline 2 & 3 & 2 & 3 & -3 & & \\
\hline 0 & 1 & 4 & 0 & 9 & & \\
\hline 2 & 4 & 6 & 3 & 6 & ) & 0 \\
\hline 3 & & & 2 & & & \\
\hline .3 & 0 & -3 & 1 & 0 & & \\
\hline 4 & 8 & 4 & 9 & 7 & 4 & 5 \\
\hline & 2 & & & 2 & & \\
\hline 3 & 0 & 3 & 0 & 9 & & \\
\hline 5 & 3 & 5 & 3 & 6 & 2 & 0 \\
\hline & 2 & & & & & \\
\hline 0 & 2 & 0 & -4 & 0 & & \\
\hline 6 & 9 & 6 & 3 & 1 & 9 & 4 \\
\hline 1 & & 6 & & 2 & & \\
\hline 4 & 4 & 6 & 2 & 4 & & \\
\hline
\end{tabular}

\begin{tabular}{|c|c|c|c|c|}
\hline \multicolumn{5}{|c|}{$0 \mathrm{X}$} \\
\hline 0 & 4 & $\vdots$ & 0 & 9 \\
\hline 0 & 0 & \pm & .2 & 0 \\
\hline 18 & 0 & 12 & 10 & 16 \\
\hline 0 & 3 & 0 & 4 & 0 \\
\hline
\end{tabular}


Table4. The Final Improvement

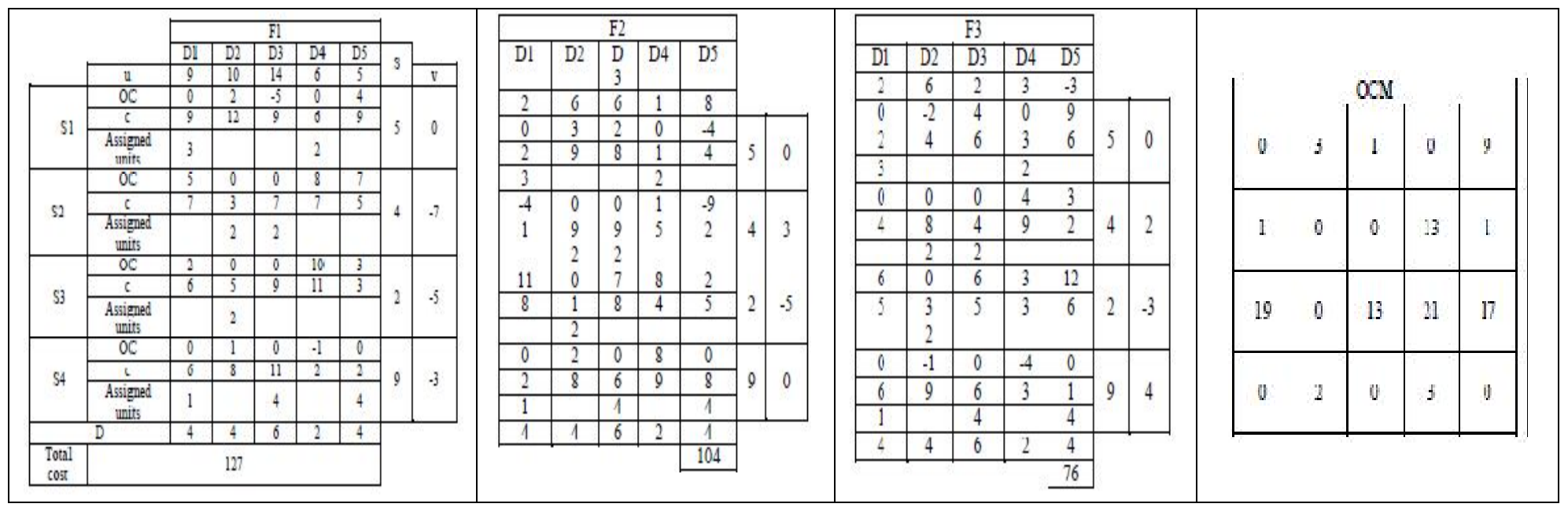

Table5. Comparison between the Proposed Technique and Others

\begin{tabular}{|c|c|c|c|c|}
\hline & $\begin{array}{c}\text { PoposedTechniue } \\
(\text { OCM })\end{array}$ & Net Deviation Appoach & InteactiveAppoachRinguest & Fuzzy Appoach \\
\hline F1 & 127 & 127 & 127 & 122 \\
\hline F2 & 104 & 104 & 104 & 106 \\
\hline F3 & 76 & 76 & 76 & 80 \\
\hline$\sum F(X)$ & 307 & 307 & 307 & 308 \\
\hline
\end{tabular}

\section{DISCUSSION}

From the following tables it appears that the proposed method can provide the solution which was provided by other methods. The proposed method stopped when the OCM doesn't have any negative variable and the set of compromise solution is as the following : $\{318, \quad[F 1=142, \quad F 2=78, \quad F 3=98]\}, \quad\{312$, $[F 1=126, F 2=92, F 3=94]\}, \quad\{309, \quad[F 1=141, F 2=86, F 3=82]\}$, $\{307,[F 1=127, F 2=104, F 3=76]\}$.

The set of compromise solution dependent on solving F1 by Vogel approximation method, and applying (OC) method to obtain the set of compromise solution was: $\{350,[\mathrm{~F} 1=102, \mathrm{~F} 2=148, \mathrm{~F} 3=100]\},\{332,[\mathrm{~F} 1=105, \mathrm{~F} 2=133, \mathrm{~F} 3=94]\}$ $,\{319,[\mathrm{~F} 1=105, \mathrm{~F} 2=126, \mathrm{~F} 3=88]\},\{314,[\mathrm{~F} 1=106, \mathrm{~F} 2=120, \mathrm{~F} 3=88]\}$, $\{310,[\mathrm{~F} 1=112, \mathrm{~F} 2=110, \mathrm{~F} 3=88]\}, 307,\{[\mathrm{~F} 1=127, \mathrm{~F} 2=104, \mathrm{~F} 3=76]\}$

The set of compromise solution dependent on solving F1 by NWC method, and applying (OC) method to obtain the set of compromise solution was: $\{342,[\mathrm{~F} 1=127, \mathrm{~F} 2=137, \mathrm{~F} 3=78]\}$, $\{316,[\mathrm{~F} 1=127, \mathrm{~F} 2=123, \mathrm{~F} 3=66]\}, \quad\{310,[\mathrm{~F} 1=126, \quad \mathrm{~F} 2=112$, $\mathrm{F} 3=72]\},\{307,[\mathrm{~F} 1=127, \mathrm{~F} 2=104, \mathrm{~F} 3=76]\}$.

From the previous results appears that the solution by getting the GCM provides the minimum set of solution which contains minimum objectives values.

\section{CONCLUSION}

There are many methods were provided to solve MOTP. In this paper, a new method was proposed to solve this kind of problems these methods provide a set of solutions or alternatives to give a decision-maker chance to choose among them. The results proved its efficiency from point of view of the set of iterations and the quality of the solution. The proposed technique wee compared to others and it was equal to two of them and superior to one of them. The decision make could depend on this method to get efficient compromise set of solutions.

\section{REFERENCES}

[1] R. A. Eizamuddin. Traffic Route Optimization for University Students with Enhanced Ant Colony Optimization Algorithm, International Journal of Advanced Trends in Computer Science and Engineering, 8(5): pp. 2668- 2672, 2019.

[2] M. Zemzami and A. Koulou. Interoperability Optimization using a modified PSO algorithm, International Journal of Advanced Trends in Computer Science and Engineering, 8(2): pp. $101-107,2019$.

[3] E.A. Youness. A Direct Approach for Finding All Efficient Solutions for Multiobjective Programming Problems, European Journal of Operational Research, 81: pp. 440-443, 1995.

[4] W. El-Wahed. A Multi-Objective Transportation Problem Under Fuzziness, Fuzzy Sets and Systems, 117: pp. 27-33, 
2001.

[5] F. Waiel and S. Abd El-Waheda. Interactive fuzzy goal programming for multi-objective transportation problems, Omega 34, pp. 158-166, 2006.

[6] P. Pandian and D. Anuradha. A New Method for Solving Bi-Objective Transportation Problems, Australian Journal of Basic and Applied Sciences, 5(10), pp. 67-74, 2011.

[7] P. Pandian. A Simple Approach for Finding a Fair Solution to Multiobjective Programming Problems, Bulletin of Mathematical Sciences and Applications, 2: pp. 21-25, 2012.

[8] S. Abdul Quddoos and M. Khalid. A New Method to Solve Bi-Objective Transportation Problem, International
Journal of Applied Mathematics. 26(5): pp. 555-563, 2013.

[9] M. Nomani. A New Approach for Solving Multi-Objective Transportation Problems, International Journal of Management Science and Engineering Management, 12: pp. 165-173, 2017.

[10] K. Murshid, S. Muneeb and A. Irfan. A Distance Based Method for Solving Multi-Objective Optimization Problems, Journal of Modern Applied Statistical Methods, 17(1): pp. 1-23, 2018.

[11]M. Rizk, A. Rizk-Allah and M. Elhoseny. A MultiObjective Transportation Model under Neutrosophic Environment, Computers and Electrical Engineering, 2018. 